\title{
Impact of a value-based insurance design for physical therapy to treat back pain on care utilization and cost
}

This article was published in the following Dove Press journal:

Journal of Pain Research

31 May 2017

Number of times this article has been viewed

\section{Daniel D Maeng' \\ Anthony Graboski \\ Peiling L Allison ${ }^{3}$ \\ Dorothy Y Fisher ${ }^{4}$ \\ John B Bulger ${ }^{2}$}

'Department of Epidemiology and Health Services Research, Geisinger Health System, ${ }^{2}$ Geisinger Health Plan, Danville, PA, ${ }^{3}$ United HealthCare Services, Inc., Milton, PA, ${ }^{4}$ Forward Health Group, Danville, PA, USA
Correspondence: Daniel D Maeng Department of Epidemiology and Health Services Research, Geisinger Health System, 100 N. Academy Avenue, MC 44-00 Danville, PA 17822, USA

$\mathrm{Tel}+\mathrm{I} 5702141688$

Email ddmaeng@geisnger.edu
Objective: To assess the impact of a value-based insurance design providing enhanced access to physical therapy (PT) for treatment of back pain on treatment patterns and cost of care.

Study design: A retrospective analysis of claims data obtained from Geisinger Health Plan (GHP). In April 2013, GHP began offering "PT bundle" - i.e., a bundle of up to five PT visits for a single one-time copay that can be renewed for another bundle of five PT visits - for its employer-based plan members with back pain.

Methods: A cohort of GHP members who were preauthorized for the PT bundle were compared against a contemporaneous cohort of GHP members who were preauthorized for PT under the standard per-visit copay arrangement between January 2013 and October 2014.

Results: Among the PT bundle cohort, the PT visit rate during the first 9 months since the PT preauthorization date had dramatically increased and then gradually decreased in subsequent months. The PT bundle was also associated with $29 \%-35 \%$ short-term reductions in emergency department visits and with $12 \%-20 \%$ reductions in primary care visits after 6 months. No significant impact on hospitalization or cost was observed.

Conclusion: Implementation of the PT bundle appears to have led to a change in the treatment pattern of back pain that is more consistent with the recommended guidelines to use more conservative management such as PT as the first-line treatment for back pain.

Keywords: back pain, physical therapy, insurance, utilization, cost of care

\section{Introduction}

Treatment of back pain is typically characterized by heterogeneous patterns that often show overutilization of low-value care (ie, high cost and low efficacy) and underutilization of high-value care (ie, low cost and high efficacy), concentrated around a small subset of the population that accounts for disproportionate amounts of health care resource utilization. ${ }^{1-4}$ Current treatment guidelines for back pain recommend using noninvasive conservative management as the first-line treatment option while avoiding more aggressive treatment options, such as high-end imaging, injections, and surgeries, at least during the early stages of the treatment. ${ }^{5-9}$ Despite the availability of such guidelines, however, the current health care system in the United States does not engage patients and providers to adhere to the guideline. ${ }^{10}$ For providers, the volume-based reimbursement system provides incentives for them to focus on using higher quantities of costlier forms of care rather than focusing on quality and value. For patients, the cost-sharing requirements imposed by the payer often do not reflect the true value of different treatment options available. 
Physical therapy (PT) is one of the potentially high-value treatment options for back pain ${ }^{11,12}$ that is currently underutilized. ${ }^{13,14}$ Although considered a form of conservative management that is consistent with the treatment guidelines, ${ }^{5,9,15}$ use of PT for treatment of back pain has remained unchanged in recent years. ${ }^{7,16}$ For patients, access to PT can be limited due to financial barriers, ${ }^{17}$ as health plans typically require preauthorization and per-session copay that can range from $\$ 10$ to $\$ 60$. To address this problem, a value-based insurance design (VBID) ${ }^{18}$ approach to the treatment of back pain has been proposed and implemented by Geisinger Health Plan (GHP), a regional health plan covering approximately half a million members in Central Pennsylvania, since 2013.

The VBID version of the PT benefit package, referred to as the "PT bundle," has been previously shown to be associated with improved member satisfaction. ${ }^{19}$ Under the PT bundle, a member who has a documented diagnosis of back pain is eligible to receive up to five PT sessions for a single copay, which is comparable to the typical copay amount for a single PT session. Upon determination of eligibility by GHP, the member is "preauthorized" to select a participating PT provider within GHP's provider network and begin receiving treatment. The member must obtain preauthorization prior to making his or her first PT visit for the health insurance coverage. The PT bundle can be renewed once for another set of five PT sessions for another copay during the same benefit period. The PT bundle therefore represents an innovative application of the principles of VBID focusing on enhanced access to a potentially high-value but underutilized treatment option to treat a condition that is prone to unnecessary and avoidable care. ${ }^{20,21}$ The aim of this study is to demonstrate, using real-world data, how the PT bundle has influenced the treatment patterns for back pain by examining its impact on care utilization and cost.

\section{Data}

This study was conducted as one of GHP's quality improvement initiatives and was therefore not subject to Geisinger's Institutional Review Board's review. The data used for this study were obtained from GHP claims data covering a 22-month period from January 2013 through October 2014. The sample included adult (ie, 18 years of age or older) GHP members with employer-sponsored health plans who had at least one International Classification of Diseases-9 (ICD-9) diagnosis codes for back pain (Supplemenatry material shows the complete list of eligible ICD-9 codes) and were preauthorized for PT during the study period.
The sample was further restricted to those members who did not switch health plans between those offering PT bundle and those without PT bundle during the study period (to avoid sample contamination) and who were preauthorized for PT on or after July 1, 2013. This cut-off date, which represents 3 months after the date at which the PT bundle first become available in April 1, 2013, was chosen to ensure that the first PT preauthorization dates capture the post-PT bundle intervention periods as accurately as possible; that is, the latter sample restriction was necessary because it was possible that a PT bundle-eligible member might have been preauthorized previously for PT prior to April 1, 2013 without the PT bundle benefit. Because the available data did not distinguish PT visits that were part of the PT bundle from those that were not, some PT visits made by the PT bundle cohort immediately after April 1, 2013 might have been incorrectly classified as PT bundle visits without this additional sample restriction. This would have led to an overestimation of PT utilization rates among the PT bundle intervention cohort immediately following the postintervention date.

The outcome variables were utilization rates and cost of care. For utilization, rates of PT and physician office visits (primary care physician (PCP) visits and specialist visits considered separately) along with rates of potentially avoidable care, defined as all-cause acute inpatient admissions, emergency department (ED) visits, and injections, were examined. All-cause rather than back-pain-related utilizations were considered because it was difficult to accurately identify back-pain-related utilizations from administratively collected claims data due to the lack of clinical information (eg, chief complaints). Correspondingly, cost of care was defined as total medical allowed amounts - the sum of all plan payments to providers plus member out-of-pocket costs for care covered under the plan's medical benefits - measured on a per-member-per-month basis. Prescription drug costs were not considered because pharmacy claims data were not available for some GHP members, as some employer groups did not provide pharmacy benefits through GHP.

\section{Methods}

A difference-in-difference approach was used to identify the PT bundle impact on the outcome variables, in which the cohort of GHP members who were preauthorized for the PT bundle was compared against a comparison cohort of GHP members who were preauthorized for PT under the standard per-visit copay requirement during the study period. As mentioned above, the post-PT intervention period was defined by the date of first PT preauthorization (ie, the index 
date) observed during the study period, which differed across the members in the sample. The difference-in-difference approach explicitly accounted for any baseline differences between the two cohorts during the pre-PT bundle intervention period as well as any temporal trends that might confound the PT bundle impact over time.

To obtain the PT bundle impact using the difference-indifference method, a set of linear regression models were estimated in which the key covariates were the binary indicator for the PT bundle intervention cohort and the indicator variable for the post-PT bundle intervention period, as well as an interaction term between the two indicator variables. The estimated coefficient on the interaction term represented the PT bundle impact on the outcome variable. Moreover, the post-PT indicator variable was further subdivided into 3-month intervals (1-3, 4-6, 7-9, and >9 months since the index date) to account for the fact that the PT bundle impact is likely to be time-dependent - that is, the effect of the PT bundle during the first 3 months (ie, short term) is likely to be different from its effect after 6-9 months (ie, long term) since the intervention.

Because the members in the sample appeared multiple times in the data set, member fixed effects were included in the regression models to account for any confounding due to time-invariant member level factors. ${ }^{22}$ The fixed effects model was particularly useful in this context due to the limited number of available covariates in the data set. In particular, the data set lacked detailed information about each member's health insurance benefit structure (eg, deductible levels, coverage limits, out-of-pocket cost sharing requirements, etc.) that might confound the PT bundle effect. Given the relatively short observation period in this study and that health insurance benefit structures tend to remain stable over the coverage period (which is usually 1 year), the member fixed effects absorbed the confounding effects of such unobserved member-level factors.

Consequently, time-invariant covariates such gender and the PT bundle cohort indicator variable were perfectly collinear with the member fixed effects and were therefore omitted from the model. However, member age and count of chronic conditions (up to nine - asthma, diabetes, congestive heart failure, chronic kidney disease, chronic obstructive pulmonary disease, coronary artery disease, hypertension, depression, and cancer), as well as the interaction terms between the two variables and calendar year indicators, were included as additional covariates in the model to capture time-varying confounding effects. In addition, to account for the correlation in the outcome variables within the same member over time, clustered standard errors were obtained and used to assess the statistical significance of the estimates. The statistical analyses were performed using Stata version 13 (StataCorp, College Station, TX, USA). Refer to the Appendix for the full regression model specification as well as the outputs.

\section{Results}

The dataset included 4,390 unique members, among which 2,197 members (50.0\%) were offered the PT bundle at some point during the study period and 2,193 members had not been offered PT bundle during the same period. The average length of observation per member for the entire sample was 17.4 months ( standard deviation $(\mathrm{SD})=4.8$ ). Among the PT bundle cohort, the average length of observation was 16.4 months ( $\mathrm{SD}=4.9$ ), and among the non-PT bundle cohort, the average length of observation was 18.4 months ( $\mathrm{SD}=4.5$ ). Prior to the index date (ie, first PT preauthorization date), the average length of observation for the PT bundle cohort was 9.0 months ( $\mathrm{SD}=3.5$ ), while the average length of observation for the non-PT bundle cohort was 8.5 months $(\mathrm{SD}=2.6$ ). After the index date, the average length of observation for the PT bundle cohort was 8.0 months ( $\mathrm{SD}=3.1$ ), while the average length of observation for the non-PT bundle cohort was 10.1 months $(\mathrm{SD}=4.3$ ).

Between the PT bundle and the non-PT bundle cohorts during the pre-PT bundle intervention period (Table 1), distribution of the available member characteristic variables were similar, as indicated by $p$-values greater than 0.05 in all the individual variables. There were, however, some statistically significant differences in the dependent variables between the two cohorts: namely, the PT bundle cohort had higher mean PT visit counts and ED visit counts, as well as higher mean physician office visit counts.

In Tables 2 and 3, "observed" amounts refer to the regression-adjusted estimates as observed among the PT bundle intervention cohort in the data. "Expected" amounts represent the regression-adjusted estimates that would have been expected among the PT bundle intervention cohort members had they not been offered PT bundle. The expected amounts are obtained by setting the post- PT bundle indicator variables to zero and recalculating the estimated values from the regression models. The difference between the observed and the expected estimates represent the PT bundle impact.

After the implementation of the PT bundle, the PT utilization rate nearly doubled relative to what was expected based on the non-PT bundle cohort during the first 3 months since the index date; it then continued to be higher than the 
Table I Pre-PT bundle intervention cohort comparison

\begin{tabular}{|c|c|c|c|}
\hline Variable & $\begin{array}{l}\text { Non-PT bundle (2,193 unique members; } \\
\text { I8,340 member-month observations) }\end{array}$ & $\begin{array}{l}\text { PT Bundle (2,197 unique members; } \\
\text { 18,467 member-month observations) }\end{array}$ & $p$-value \\
\hline Female & $\mathrm{II}, 04 \mathrm{I}(60.2 \%)$ & $10,727(58.1 \%)$ & 0.188 \\
\hline Age: $<40$ years old & $4,806(26.2 \%)$ & $4,538(24.6 \%)$ & 0.248 \\
\hline Age: $40-49$ & $4,638(25.3 \%)$ & $4,510(24.4 \%)$ & 0.539 \\
\hline Age: $50-59$ & $5,460(29.8 \%)$ & $5,856(31.7 \%)$ & 0.199 \\
\hline Age: $60+$ & $3,436(18.7 \%)$ & $3,563(19.3 \%)$ & 0.666 \\
\hline Asthma & $3,189(17.4 \%)$ & $3,403(18.4 \%)$ & 0.404 \\
\hline Coronary artery disease & $\mathrm{I}, 228(6.7 \%)$ & $\mathrm{I}, 293(7 \%)$ & 0.709 \\
\hline Cancer & $334(1.8 \%)$ & $398(2.2 \%)$ & 0.430 \\
\hline Congestive heart failure & $9 \mathrm{I}(0.5 \%)$ & $1 \mathrm{I} 8(0.6 \%)$ & 0.548 \\
\hline Chronic kidney disease & 291 (1.6\%) & $266(1.4 \%)$ & 0.710 \\
\hline Chronic obstructive pulmonary disease & $390(2.1 \%)$ & $534(2.9 \%)$ & 0.124 \\
\hline Depression & 3,098 (16.9\%) & $2,976(16.1 \%)$ & 0.517 \\
\hline Diabetes & $2,134(11.6 \%)$ & 2,051 (II.I\%) & 0.609 \\
\hline Hypertension & $6,049(33 \%)$ & $5,77 \mid(31.3 \%)$ & 0.253 \\
\hline No. of comorbidity: 0 & 8,155 (44.5\%) & $8,325(45.1 \%)$ & 0.699 \\
\hline No. of comorbidity: I & $5,721(31.2 \%)$ & $5,615(30.4 \%)$ & 0.589 \\
\hline No. of comorbidity: $2+$ & $4,464(24.3 \%)$ & $4,527(24.5 \%)$ & 0.900 \\
\hline Mean total medical allowed \$ PMPM (SD) & $771(5,222)$ & $843(4,498)$ & 0.230 \\
\hline Mean PT visit counts ${ }^{a}(S D)$ & $104(750)$ & $145(1,121)$ & 0.012 \\
\hline Mean acute IP admit counts ${ }^{\mathrm{a}}(\mathrm{SD})$ & $9(98)$ & II (I30) & 0.138 \\
\hline Mean ED visit counts ${ }^{a}(\mathrm{SD})$ & $29(187)$ & $46(276)$ & 0.000 \\
\hline Mean PCP visit counts $(\mathrm{SD})$ & $258(538)$ & $328(723)$ & 0.000 \\
\hline Mean specialist visit counts ${ }^{\mathrm{a}}(\mathrm{SD})$ & $221(550)$ & $291(730)$ & 0.000 \\
\hline Mean injection counts $(\mathrm{SD})$ & $18(227)$ & $2 \mid(3 \mid 3)$ & 0.413 \\
\hline
\end{tabular}

Note: aPer I,000 members per month.

Abbreviations: PMPM, per-member-per-month; SD, standard deviation; PT, physical therapy; IP, inpatient; ED, emergency department; PCP, primary care physician.

Table 2 Impact of PT bundle on PT utilization and total medical cost

\begin{tabular}{|c|c|c|c|c|c|c|c|c|c|}
\hline \multirow[t]{2}{*}{ Observation period } & \multirow[t]{2}{*}{$\begin{array}{l}\text { \#Member-month } \\
\text { observations ( } \mathbf{N})\end{array}$} & \multicolumn{4}{|c|}{$\begin{array}{l}\text { Count of PT visit } \\
\text { (per I,000 per month) }\end{array}$} & \multicolumn{4}{|c|}{$\begin{array}{l}\text { Total medical allowed } \\
\text { (\$ PMPM) }\end{array}$} \\
\hline & & Obs & Exp & Diff & $p$-value & Obs & Exp & Diff & $p$-value \\
\hline Prior to PT preauthorization & 18,467 & 183 & 183 & 0 & - & 828 & 828 & 0 & - \\
\hline After PT Auth: I-3 months & 6,483 & 3,145 & $\mathrm{I}, 770$ & $\mathrm{I}, 375$ & 0.000 & 1,346 & $\mathrm{I}, \mathrm{I} 44$ & 203 & 0.059 \\
\hline After PT Auth: 4-6 months & 5,785 & 512 & 246 & 266 & 0.000 & 994 & 824 & 170 & 0.096 \\
\hline After PT Auth: 7-9 months & 3,517 & 270 & $|8|$ & 89 & 0.068 & 883 & 686 & 197 & 0.106 \\
\hline After PT Auth: > 9 months & $\mathrm{I}, 80 \mathrm{I}$ & 147 & 313 & -166 & 0.005 & 809 & 577 & 231 & 0.178 \\
\hline
\end{tabular}

Note: " represents the number of member-month observations in the sample rather than the number of unique members. '-' indicates not available.

Abbreviations: PT, physical therapy; Obs, observed; Exp, expected; Diff, difference; PMPM, per-member-per-month.

Table 3 Impact of PT bundle on potentially avoidable care

\begin{tabular}{|c|c|c|c|c|c|c|c|c|c|c|c|c|}
\hline \multirow[t]{2}{*}{ Observation period } & \multicolumn{4}{|c|}{$\begin{array}{l}\text { Count of IP acute } \\
\text { (per I,000 per month) }\end{array}$} & \multicolumn{4}{|c|}{$\begin{array}{l}\text { Count of ED visits } \\
\text { (per } 1,000 \text { per month) } \\
\end{array}$} & \multicolumn{4}{|c|}{$\begin{array}{l}\text { Count of injections } \\
\text { (per } 1,000 \text { per month) }\end{array}$} \\
\hline & Obs & Exp & Diff & $p$-value & Obs & Exp & Diff & $\mathbf{p}$ & Obs & Exp & Diff & $p$-value \\
\hline Prior to PT preauthorization & 10.0 & 10.0 & 0.0 & - & 39.5 & 39.5 & 0.0 & - & 21.2 & 21.2 & 0.0 & - \\
\hline After PT Auth: I-3 months & 9.4 & 9.1 & 0.3 & 0.890 & 60.2 & 56.2 & 4.0 & 0.515 & 55.4 & 45.7 & 9.7 & 0.331 \\
\hline After PT Auth: 4-6 months & 7.3 & 10.8 & -3.5 & 0.206 & 27.5 & 38.7 & -11.2 & 0.030 & 84.4 & 63.8 & 20.6 & 0.115 \\
\hline After PT Auth: 7-9 months & 8.1 & 7.6 & 0.5 & 0.862 & 22.4 & 34.4 & -12.0 & 0.036 & 44.1 & 39.2 & 4.9 & 0.689 \\
\hline After PT Auth: >9 months & 11.3 & 7.2 & 4.1 & 0.278 & 35.4 & 38.9 & -3.5 & 0.662 & 3.5 & 23.3 & -19.8 & 0.152 \\
\hline
\end{tabular}

Notes: '-' indicates not available.

Abbreviations: PT, physical therapy; IP, inpatient; ED, emergency department; Obs, observed; Exp, expected; Diff, difference.

expected during the following 4 to 9 -month period (Table 2). $\quad$ it is below the expected level by $53.0 \%(p=0.005)$ after 9 This increase in the PT utilization is then subsequently fol- months. The impact of the PT bundle on total medical cost, lowed by a statically significant decline to a point at which however, was not statistically significant at $5 \%$ level. Also, 
while PT bundle was not significantly associated with acute inpatient admissions (Table 3), PT bundle was associated with $28.9 \%-34.9 \%$ reductions $(p<0.05)$ in ED visits during the 4 to 9 -month period since the index date. Moreover, although not statistically significant at 5\% level, PT bundle appeared to be associated with lower utilization of injections after 9 months.

The PT bundle was significantly associated with reductions in PCP visits after 6 months since the index date (Table 4). However, PT bundle was associated with significant increases in specialist visits during the first 6 months since the index date. Subsequently, after 9 months, PT bundle was the associated with $35.1 \%$ lower rate of specialist visits, which was statistically significant at the $5 \%$ level ( $p=0.007)$.

Figure 1 reproduces the results shown in Table 1 for the impact of the PT bundle on PT utilization. The most notable feature of Figure 1 is the peak PT visit rate among the PT bundle cohort during the first 3 months immediately following the index date, which is then followed by a steady and gradual decline in subsequent months. This is in contrast with the expected pattern based on the non-PT bundle cohort. The expected PT visit rate shows a smaller peak during the early months, then a stable period during which the PT visit rate falls back nearly to the preindex period level, and then subsequently after the first 9 months, the PT visit rate among the non-PT bundle cohort significantly exceeds that of the PT bundle cohort.

\section{Discussion}

The results suggest that the PT bundle, which follows the main principle of VBID by lowering financial barriers to PT, may have altered the course of treatment for back pain in such a way it is more consistent with the well-established treatment guidelines for back pain. The guideline recommends using conservative management such as over-the-counter painrelief medications and PT as the first-line treatment, ${ }^{16}$ while avoiding more aggressive and costlier treatment options. ${ }^{20,23}$ The rapid uptake of PT coupled with the reductions in ED visits among the PT bundle cohort in the short term therefore indicates that patients might have indeed chosen to use PT as the first-line treatment option instead of ED. In addition, the results show reductions of approximately $85 \%$ in injections starting in 9 months after the index date, albeit not statistically significant at the $5 \%$ level. The long-term reductions in injection rate are consistent with the expectation that

Table 4 Impact of PT bundle on physician office visits

\begin{tabular}{|c|c|c|c|c|c|c|c|c|}
\hline \multirow[t]{2}{*}{ Observation period } & \multicolumn{4}{|c|}{$\begin{array}{l}\text { Count of PCP visits } \\
\text { (per } 1,000 \text { per month) }\end{array}$} & \multicolumn{4}{|c|}{$\begin{array}{l}\text { Count of specialist visits } \\
\text { (per I,000 per month) }\end{array}$} \\
\hline & Obs & Exp & Diff & $p$-value & Obs & Exp & Diff & $p$-value \\
\hline Prior to PT preauthorization & 318 & 318 & 0 & - & 263 & 263 & 0 & - \\
\hline After PT Auth: I-3 months & 466 & 437 & 30 & 0.059 & 497 & 420 & 78 & 0.000 \\
\hline After PT Auth: 4-6 months & 274 & 271 & 3 & 0.799 & 366 & 295 & 70 & 0.000 \\
\hline After PT Auth: 7-9 months & 226 & 257 & -31 & 0.044 & 289 & 272 & 17 & 0.400 \\
\hline After PT Auth: >9 months & 216 & 269 & -53 & 0.009 & 137 & 211 & -74 & 0.007 \\
\hline
\end{tabular}

Abbreviations: PT, physical therapy; PCP, primary care physician; Obs, observed; Exp, expected; Diff, difference.

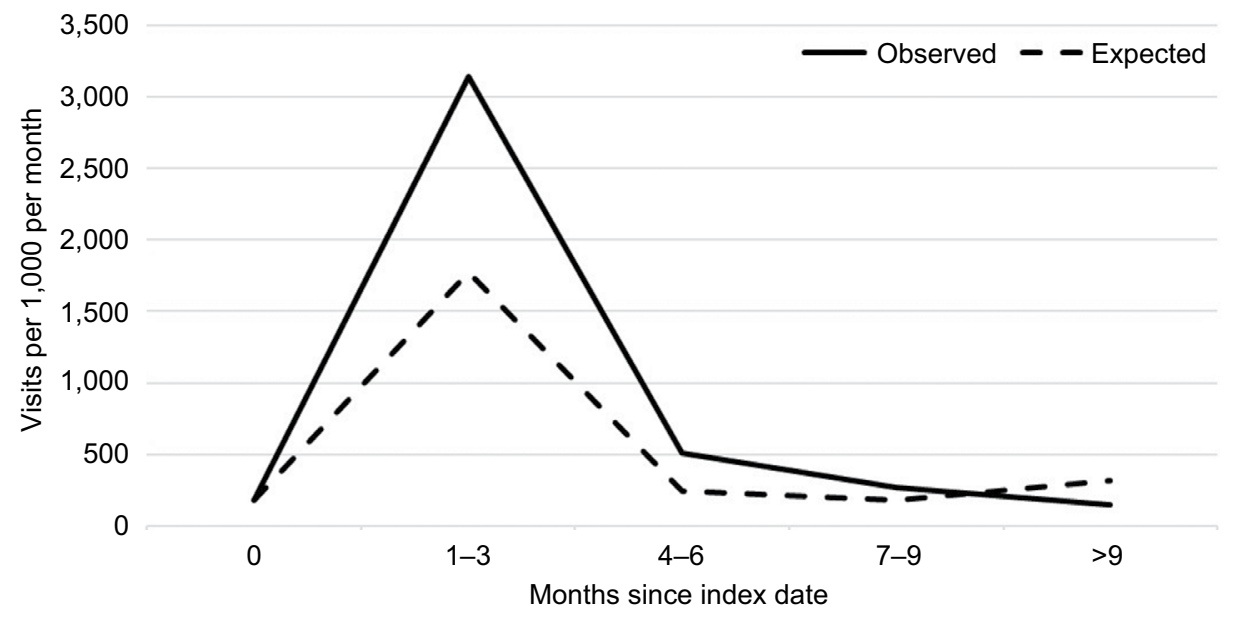

Figure I Impact of PT bundle on PT visit rates. Abbreviation: PT, physical therapy. 
increased use of PT as the first-line treatment for back pain has led to lower use of potentially avoidable low-value care.

The results also suggest that among the PT bundle cohort, PT visits might have been complementary to physician office visits, as indicated by the similar patterns of increases and decreases of PCP and specialist visit rates that roughly mirror the PT visit patterns. That is, PCP and specialist visit rates appear to have increased during the first several months following the index date and then decreased significantly relative to the non-PT bundle cohort, as did the PT visit rates. This implies that at least some of the potentially avoidable care in ED might have been replaced with additional physician office visits and PT visits. To the extent that much of care rendered in ED for back pain consists of diagnostic testing and temporary relief of symptoms via episodic use of opioids, ${ }^{23}$ the increased reliance on physician care at the expense of ED utilization implies potential benefits to patients via improved care coordination, longitudinal care management, and subsequently better long-term health outcomes.

At the same time, PT bundle does not appear to be associated with any significant total medical cost savings, either short-term or long-term. There are two potential explanations: First, the cost savings due to the reductions in ED visits, injections, and long-term physician visits may have been offset by the increased costs associated with the large increase in the PT utilization. Second, the fact that PT bundle does not appear to be associated with inpatient admission rates, which is typically a major cost driver, implies that PT bundle may not have influenced use of surgery to manage back pain. To the extent that surgery is appropriate for certain types of back pain $^{24}$ and that PT may not be effective for such conditions, the results suggest that PT bundle may have impacted only the treatment patterns of certain types of back pain for which discretionary, nonsurgical treatment options are available and prevalent in the currents standard of care.

Limitations of this study include reliance on observational data that were collected for administrative purposes and limited availability of patient characteristics and relevant clinical information in the available data. Consequently, the results may be subject to unobserved bias and confounding. In addition, generalizability of the findings is unknown, because PT bundle was offered to members of a single regional health plan whose membership predominantly consisted of Caucasian population residing in Central Pennsylvania. In addition, the impact of the PT bundle on prescription drug use and costs were not considered due to the lack of pharmacy claims data for some of the patients in the sample. To the extent that increased use of PT may reduce inappropriate use of opioids, this study potentially underestimates the overall benefits of the PT bundle. This is an important area for future research.

\section{Conclusion}

Implementation of the PT bundle appears to have led to a change in the treatment pattern of back pain that is more consistent with the recommended guideline to use more conservative management such as PT as the first-line treatment for back pain. Although no significant total cost saving was observed, the results suggest that a value-based approach to enhance patients' access to PT has a potential not only to improve patient outcome via better alignment of treatment patterns with the recommended guidelines but also to enhance patient experience of care.

\section{Disclosure}

All the authors were employees of Geisinger Health System at the time the study was conducted. The study was conducted as a part of the authors' employment with Geisinger Health System. No external funding was provided to support this research. The authors report no other conflicts of interest in this work.

\section{Reference}

1. Deyo RA, Mirza SK, Martin BI. Back pain prevalence and visit rates: estimates from U.S. national surveys, 2002. Spine. 2006;31(23):2724-2727.

2. Stewart WF, Yan X, Boscarino JA, et al. Patterns of health care utilization for low back pain. J Pain Res. 2015;8:523-535.

3. Andersson GB. Epidemiological features of chronic low-back pain. Lancet. 1999;354(9178):581585

4. Maeng DD, Stewart WF, Yan X, et al. Use of electronic health records for early detection of high-cost, low back pain patients. Pain Res Manag. 2015;20(5):234-240.

5. van Tulder MW, Koes BW, Bouter LM. Conservative treatment of acute and chronic nonspecific low back pain. A systematic review of randomized controlled trials of the most common interventions. Spine. 1997;22(18):2128-2156.

6. Koes BW, van Tulder MW, Ostelo R, Kim Burton A, Waddell G. Clinical guidelines for the management of low back pain in primary care: an international comparison. Spine. 2001;26(22):2504-2513.

7. Williams CM, Maher CG, Hancock MJ, et al. Low back pain and best practice care: a survey of general practice physicians. Arch Intern Med. 2010;170(3):271-277.

8. Chou R, Deyo R, Friedly J, et al. Noninvasive Treatments for Low Back Pain. Rockville, MD: Agency for Healthcare Research and Quality; 2016.

9. Qaseem A, Wilt TJ, McLean RM, Forciea MA, Clinical Guidelines Committee of the American College of P. Noninvasive treatments for acute, subacute, and chronic low back pain: a clinical practice guideline from the American College of Physicians. Ann Intern Med. 2017;166(7):514-530.

10. Fritz JM. Physical therapy in a value-based healthcare world. J Orthop Sports Phys Ther. 2012;42(1):1-2.

11. Horn ME, Brennan GP, George SZ, Harman JS, Bishop MD. A value proposition for early physical therapist management of neck pain: a retrospective cohort analysis. BMC Health Serv Res. 2016;16:253.

12. Childs JD, Fritz JM, Wu SS, et al. Implications of early and guideline adherent physical therapy for low back pain on utilization and costs. BMC Health Serv Res. 2015;15:150. 
13. Freburger JK, Carey TS, Holmes GM. Physical therapy for chronic low back pain in North Carolina: overuse, underuse, or misuse? Phys Ther. 2011;91(4):484-495.

14. Gellhorn AC, Chan L, Martin B, Friedly J. Management patterns in acute low back pain: the role of physical therapy. Spine. 2012;37(9): 775-782.

15. Savigny P, Watson P, Underwood M, Guideline Development Group. Early management of persistent non-specific low back pain: summary of NICE guidance. BMJ. 2009;338:b1805.

16. Mafi JN, McCarthy EP, Davis RB, Landon BE. Worsening trends in the management and treatment of back pain. JAMA Intern Med. 2013;173(17):1573-1581.

17. Dolot J, Viola D, Shi Q, Hyland M. Impact of out-of-pocket expenditure on physical therapy utilization for nonspecific low back pain: secondary analysis of the medical expenditure panel survey data. Phys Ther. 2016;96(2):212-221.

18. Chernew ME, Rosen AB, Fendrick AM. Value-based insurance design. Health Affairs. 2007;26(2):w195-203.
19. Maeng DD, Fisher DY, Graboski A, et al. Impact of a value-based insurance design for back pain on health plan member satisfaction and its implications for patient outcomes. Popul Health Manag. 2015;18(3):203-208.

20. Fritz JM, Brennan GP, Hunter SJ. Physical therapy or advanced imaging as first management strategy following a new consultation for low back pain in primary care: associations with future health care utilization and charges. Health Serv Res. 2015;50(6):1927-1940.

21. Fritz JM, Childs JD, Wainner RS, Flynn TW. Primary care referral of patients with low back pain to physical therapy: impact on future health care utilization and costs. Spine. 2012;37(25):2114-2121.

22. Cameron AC, Trivedi PK. Microeconometrics Using Stata. College Station, TX: Stata Press; 2009.

23. Friedman BW, Chilstrom M, Bijur PE, Gallagher EJ. Diagnostic testing and treatment of low back pain in United States emergency departments: a national perspective. Spine. 2010;35(24):E1406-1411.

24. Chou R, Baisden J, Carragee EJ, Resnick DK, Shaffer WO, Loeser JD. Surgery for low back pain: a review of the evidence for an American Pain Society Clinical Practice Guideline. Spine. 2009;34(10):1094-1109. 


\section{Supplementary material}

$\mathrm{Y}_{i t}=\alpha_{0}+\alpha_{1}$ PTBundle $_{i}+\alpha_{2}$ PTPost $_{i t}+\alpha_{3}\left(\right.$ PTBundle $_{i} \times$ PTPost $\left._{i t}\right)+\alpha_{4} \mathrm{X}_{i t}+\alpha_{5}$ Year $_{t}+\mathrm{v}_{i}+\varepsilon_{i t}$

$\mathrm{Y}_{i t}=$ dependent variable (cost of care or utilization) for member $i$ at time $t$

PTBundle $_{i}=$ binary indicator for whether member $i$ belongs to the PT bundle intervention cohort

PTPost $_{i t}=$ a set of binary indicators for the number of months since the PT preauthorization date (ie, post-PT bundle intervention period)

PTBundle $_{i} \times$ PTPost $_{i t}=$ a set of interaction terms between PTBundle ${ }_{i}$ and PTPost ${ }_{i t}$

$\mathrm{X}_{i t}=$ a vector of time-varying characteristics for member $i$ at time $t$ (ie, age and number of comorbid conditions, as well as the interaction terms between the two covariates)

Year $_{t}=$ Calendar year indicator variable (2013 or 2014)

$\mathrm{v}_{i}=$ fixed effect for member $i$

$\varepsilon_{i t}=$ error term for member $i$ at time $t$

The main coefficients of interest are represented by $\alpha_{3}$, which represents the change in the dependent variable $\mathrm{Y}_{i t}$ above and beyond what is observed among the non-PT bundle comparison group during the pre-PT bundle intervention period as well as between the pre-post periods over time. Note that the member fixed effect $\mathrm{v}_{i}$ captures all time-invariant characteristics of member $i$, both observed and unobserved. Consequently, $\alpha_{1}$ is not separately identified.

Table SI Member fixed effects linear regression model full output - cost and utilization of PT, IP Acute, and ED

\begin{tabular}{|c|c|c|c|c|c|c|c|c|}
\hline \multirow[t]{2}{*}{ Covariate } & \multicolumn{2}{|c|}{ Total medical allowed } & \multicolumn{2}{|l|}{ PT visits } & \multicolumn{2}{|c|}{ IP acute admits } & \multicolumn{2}{|l|}{ ED visits } \\
\hline & Coefficient & $p$-value & Coefficient & $p$-value & Coefficient & $p$-value & Coefficient & $p$-value \\
\hline Male & (reference) & - & (reference) & - & (reference) & - & (reference) & - \\
\hline Female $^{\mathrm{a}}$ & (omitted) & - & (omitted) & - & (omitted) & - & (omitted) & - \\
\hline Non-PT bundle cohort & (reference) & - & (reference) & - & (reference) & - & (reference) & - \\
\hline PT bundle cohort ${ }^{\mathrm{a}}$ & (omitted) & - & (omitted) & - & (omitted) & - & (omitted) & - \\
\hline Post-PT: 0 months & (reference) & - & (reference) & - & (reference) & - & (reference) & - \\
\hline Post-PT: I-3 months & 256.311 & 0.000 & 1.698 & 0.000 & -0.001 & 0.498 & 0.011 & 0.002 \\
\hline Post-PT: 4-6 months & -53.501 & 0.516 & 0.178 & 0.000 & 0.001 & 0.635 & -0.008 & 0.039 \\
\hline Post-PT: 7-9 months & -164.929 & 0.092 & 0.106 & 0.002 & -0.002 & 0.435 & -0.013 & 0.006 \\
\hline Post-PT: $>9$ months & -191.408 & 0.077 & 0.103 & 0.005 & -0.002 & 0.450 & -0.008 & 0.100 \\
\hline PT bundle $\times \mathrm{I}-3$ months & 202.779 & 0.059 & 1.375 & 0.000 & 0.000 & 0.890 & 0.004 & 0.515 \\
\hline PT bundle $\times 4-6$ months & 170.134 & 0.096 & 0.266 & 0.000 & -0.003 & 0.206 & -0.011 & 0.030 \\
\hline PT bundle $\times 7-9$ months & 197.392 & 0.106 & 0.089 & 0.068 & 0.001 & 0.862 & -0.012 & 0.036 \\
\hline PT bundle $\times>9$ months & 231.301 & 0.178 & -0.166 & 0.005 & 0.004 & 0.278 & -0.004 & 0.662 \\
\hline Year 2013 & (reference) & - & (reference) & - & (reference) & - & (reference) & - \\
\hline Year 2014 & 139.812 & 0.030 & -0.104 & 0.001 & 0.001 & 0.680 & 0.013 & 0.000 \\
\hline Age: $<40$ years old & (reference) & - & (reference) & - & (reference) & - & (reference) & - \\
\hline Age: $40-49$ & 399.490 & 0.000 & 1.430 & 0.000 & 0.000 & 0.859 & 0.094 & 0.000 \\
\hline Age: $50-59$ & -683.874 & 0.570 & 3.473 & 0.000 & 0.002 & 0.503 & 0.100 & 0.000 \\
\hline Age: $60+$ & -74.579 & 0.951 & 4.640 & 0.000 & 0.002 & 0.559 & 0.103 & 0.000 \\
\hline No. of comorbidity: 0 & (reference) & - & (reference) & - & (reference) & - & (reference) & - \\
\hline No. of comorbidity: I & 534.154 & 0.003 & 0.027 & 0.588 & 0.016 & 0.073 & 0.004 & 0.748 \\
\hline No. of comorbidity: $2+$ & 833.048 & 0.004 & 0.012 & 0.919 & 0.012 & 0.117 & 0.095 & 0.001 \\
\hline Age $40-49 \times$ No. of comorbidity I & 219.420 & 0.450 & 0.021 & 0.857 & -0.006 & 0.565 & 0.031 & 0.091 \\
\hline Age $40-49 \times$ No. of comorbidity 2 & 704.645 & 0.152 & 0.075 & 0.670 & 0.001 & 0.907 & -0.054 & 0.092 \\
\hline Age $50-59 \times$ No. of comorbidity I & $|72.34|$ & 0.447 & 0.066 & 0.397 & -0.014 & 0.142 & 0.004 & 0.787 \\
\hline Age $50-59 \times$ No. of comorbidity 2 & 232.493 & 0.481 & 0.007 & 0.960 & 0.002 & 0.843 & -0.061 & 0.037 \\
\hline Age $60+\times$ No. of comorbidity I & 152.904 & 0.516 & 0.177 & 0.041 & -0.005 & 0.590 & 0.023 & 0.126 \\
\hline Age $60+\times$ No. of comorbidity 2 & -60.273 & 0.881 & 0.241 & 0.077 & -0.005 & 0.650 & -0.074 & 0.014 \\
\hline Constant & 475.451 & 0.424 & -2.199 & 0.000 & 0.004 & 0.048 & -0.051 & 0.000 \\
\hline $\begin{array}{l}\text { N No. of member-month; } \\
\text { No. of member) }\end{array}$ & 76,$457 ; 4,390$ & & 76,$457 ; 4,390$ & & 76,$457 ; 4,390$ & & 76,$457 ; 4,390$ & \\
\hline
\end{tabular}

Notes: aOmitted due to collinearity with patient fixed effects. '-' indicates not available.

Abbreviations: PT, physical therapy; IP, inpatient; ED, emergency department. 
Table S2 Member fixed effects linear regression model full output - physician office visits and injection

\begin{tabular}{|c|c|c|c|c|c|c|}
\hline \multirow[t]{2}{*}{ Covariate } & \multicolumn{2}{|l|}{ PCP visits } & \multicolumn{2}{|c|}{ Specialist visits } & \multicolumn{2}{|c|}{ Injection counts } \\
\hline & Coefficient & $p$-value & Coefficient & $p$-value & Coefficient & $p$-value \\
\hline Male & (reference) & - & (reference) & - & (reference) & - \\
\hline Female $^{\mathrm{a}}$ & (omitted) & - & (omitted) & - & (omitted) & - \\
\hline Non-PT bundle cohort & (reference) & - & (reference) & - & (reference) & - \\
\hline PT bundle cohort & (omitted) & - & (omitted) & - & (omitted) & - \\
\hline Post-PT: 0 months & (reference) & - & (reference) & - & (reference) & - \\
\hline Post-PT: I-3 months & 0.109 & 0.000 & 0.124 & 0.000 & 0.024 & 0.000 \\
\hline Post-PT: 4-6 months & -0.062 & 0.000 & -0.002 & 0.846 & 0.043 & 0.000 \\
\hline Post-PT: 7-9 months & -0.080 & 0.000 & -0.023 & 0.109 & 0.020 & 0.015 \\
\hline Post-PT: >9 months & -0.096 & 0.000 & -0.059 & 0.000 & 0.008 & 0.344 \\
\hline PT bundle $\times \mathrm{I}-3$ months & 0.030 & 0.059 & 0.078 & 0.000 & 0.010 & 0.331 \\
\hline PT bundle $\times 4-6$ months & 0.003 & 0.799 & 0.070 & 0.000 & 0.021 & 0.115 \\
\hline PT bundle $\times 7-9$ months & -0.031 & 0.044 & 0.017 & 0.400 & 0.005 & 0.689 \\
\hline PT bundle $x>9$ months & -0.053 & 0.009 & -0.074 & 0.007 & -0.020 & 0.152 \\
\hline Year 2013 & (reference) & - & (reference) & - & (reference) & - \\
\hline Year 2014 & 0.047 & 0.000 & 0.063 & 0.000 & 0.001 & 0.804 \\
\hline Age: $<40$ years old & (reference) & - & (reference) & - & (reference) & - \\
\hline Age: $40-49$ & 0.758 & 0.000 & 0.278 & 0.000 & -0.017 & 0.000 \\
\hline Age: 50-59 & $\mathrm{I} .105$ & 0.016 & -0.110 & 0.827 & -0.041 & 0.000 \\
\hline Age: $60+$ & 1.415 & 0.002 & -0.166 & 0.741 & -0.064 & 0.000 \\
\hline No. of comorbidity: 0 & (reference) & - & (reference) & - & (reference) & - \\
\hline No. of comorbidity: I & 0.099 & 0.000 & 0.120 & 0.000 & 0.015 & 0.029 \\
\hline No. of comorbidity: $2+$ & 0.180 & 0.000 & 0.206 & 0.000 & 0.023 & 0.135 \\
\hline Age $40-49 \times$ No. of comorbidity I & 0.046 & 0.240 & -0.005 & 0.915 & -0.004 & 0.904 \\
\hline Age $40-49 \times$ No. of comorbidity 2 & 0.031 & 0.584 & 0.097 & 0.204 & 0.011 & 0.653 \\
\hline Age $50-59 \times$ No. of comorbidity I & 0.015 & 0.674 & -0.006 & 0.870 & -0.003 & 0.836 \\
\hline Age $50-59 \times$ No. of comorbidity 2 & -0.024 & 0.632 & 0.071 & 0.264 & 0.002 & 0.934 \\
\hline Age $60+\times$ No. of comorbidity I & 0.037 & 0.323 & 0.008 & 0.841 & 0.034 & 0.071 \\
\hline Age $60+\times$ No. of comorbidity 2 & -0.010 & 0.852 & 0.043 & 0.468 & 0.041 & 0.072 \\
\hline Constant & -0.579 & 0.011 & 0.149 & 0.548 & 0.035 & 0.000 \\
\hline $\mathrm{N}$ (No. of member-month; No. of member) & 76,$457 ; 4,390$ & & 76,$457 ; 4,390$ & & 76,$457 ; 4,390$ & \\
\hline
\end{tabular}

Note: 'Omitted due to collinearity with patient fixed effects. '-' indicates not available.

Abbreviations: PCP, primary care physician; PT, physical therapy. 
Table S3 Back pain-related ICD-9 codes eligible for PT bundle

\begin{tabular}{ll}
\hline Diagnosis & Codes \\
\hline Lumbar ICD 9 Codes & \\
SI dysfunction & 739.4 \\
Sacroilitis & 720.2 \\
Scaitica & 724.3 \\
Scoliosis & 737.30 \\
Back pain & 724.2 \\
Back sprain & 847.9 \\
Lumbar pain & 724.2 \\
Lumbar sprain & 847.2 \\
Lumbosacral strain & 846.0 \\
Lumbar stenosis & 724.02 \\
Lumbar spondylosis & 721.3 \\
Lumbar HNP & 722.10 \\
Lumbar DDD & 722.52 \\
Lumbar radiculopathy & 724.4 \\
Lumbar disc displacement & 722.10 \\
Compression fracture & 733.10 \\
Coccyx sprain & 847.4 \\
Spondylolithesis & 756.12 \\
Cervical ICD 9 Codes & \\
Headache & 784.0 \\
Tension headache & 307.81 \\
Cervical stenosis & 723.0 \\
Cervical pain & 723.1 \\
Cervical sprain & 847.0 \\
Cervical spondylosis & 721.0 \\
Cervical radiculopathy & 723.4 \\
Cervical HNP & 722.0 \\
Cervical DDD & 722.4 \\
Thoracic ICD 9 Codes & \\
Thoracic pain & 724.1 \\
Thoracic sprain & 847.1 \\
Thoracic DDD & 722.51 \\
\hline Ahoracic HNP/disc displacement & 722.11 \\
\hline
\end{tabular}

Abbreviations: DDD, degenerative disc disease; HNP, herniated nucleus pulposus; ICD, International Classification of Diseases; PT, physical therapy; SI, sacroiliac.

\section{Publish your work in this journal}

The Journal of Pain Research is an international, peer reviewed, open access, online journal that welcomes laboratory and clinical findings in the fields of pain research and the prevention and management of pain. Original research, reviews, symposium reports, hypothesis formation and commentaries are all considered for publication.

\section{Dovepress}

The manuscript management system is completely online and includes a very quick and fair peer-review system, which is all easy to use. Visit http://www.dovepress.com/testimonials.php to read real quotes from published authors. 